\title{
TOWARDS MOBILE AND INTELLIGENT RAILWAY TRANSPORT: A REVIEW OF RECENT ERTMS RELATED RESEARCH
}

\author{
VAHID RANJBAR \& NILS O. E. OLSSON \\ KTH Royal Institute of Technology, Department of Transport Science, Sweden \\ Norwegian University of Science and Technology, Department of Production and Quality Engineering, Norway
}

\begin{abstract}
The development of the European Railway Traffic Management System (ERTMS) throughout Europe over the last two decades to remove obstacles to providing an interoperable railway network has been facing several challenges. This study briefly highlights several of these challenges by analysing the current architecture of ERTMS and main concerns such as its implementation, the interoperability of communication, formal methods, hybrid ERMS (Level 3), safety, and human factors. This study has taken a systematic approach to data collection and analysis through a review of the current literature. The studies examined illustrate that it is necessary to reduce the number of components in order to pivot the system toward mobile equipment, autonomous trains, and decentralised communication. In the area of formalisation, every supplier and responsible party conducting modelling and testing of the system uses a different tool. Here, we conclude it would be appropriate to develop a robust and reliable tool for modelling, formalisation, testing and the validation of critical safety systems in the railway industry according to its particular specifications and functionalities, e.g. for ERTMS L3, including moving block, virtual coupling, and Automatic Train Operation (ATO). To bridge gaps between human operation and new technologies, reduce human error, and increase performance in the railway industry, a stronger emphasis on the development of employees' skills with new technologies is highly recommended. In order to build upon previous investments in ERTMS and to guarantee backwards and forwards interoperability, it is necessary to exploit hybrid solutions and to gradually update the current systems.
\end{abstract}

Keywords: implementation of ERTMS, GNSS-based train positioning, adaptable communication system, interoperability, train integrity monitoring system, virtual coupling.

\section{INTRODUCTION}

This study aims to identify the current challenges facing the European Rail Traffic Management System (ERTMS) to achieve a mobile and intelligent railway transport system by carrying out a literature review. This literature review is based on a series of database searches using keywords such as "ERTMS OPERATION" and "ERTMS ISSUES". This study considered only research with a high number of citations, and a recent date of publication. Accordingly, this review draws on studies published since 2015. The studies reviewed are summarised and categorised according to their discussions of critical issues.

After three decades of operation, GSM-R cannot satisfy all the needs of European Train Control System (ETCS) due to issues related to its low capacity for data and voice transmission, latency, interferences, and a further lack of safety requirements for communication system in next generation railways [1].

There are some candidates to replace GSM-R, which is based on the 2nd Generation ( $2 \mathrm{G})$ telecommunication system. One candidate is Long Term Evolution-Railway (LTE-R), which is based on $4 \mathrm{G}$ protocol; however, there is reason to hold off on implementing a new $4 \mathrm{G}$ system due to the imminent availability of better 5G networks. As a consequence, there is greater support from the International Union of Railways (UIC) to use a flexible 5G system, relying as well on other technologies [2]. 
The safe movement of trains during their operation along the railway network requires a safe and reliable positioning system. ERTMS Level 1 and Level 2 both rely on track circuits and axle counters for positioning information. In ERTMS HL3 (Hybrid Level 3), the positioning system relies on data provided by Trackside Train Detection (TTD) using either fixed block technology equipment (track circuit and axle counter) or Positive Train Detection (PTD). The train detection and positioning are the responsibility of an on-board subsystem, depending on the level of operation. For example, in Level 3, the position of the train should be provided continually to chasing and chased trains to fulfil the requirements of moving block technology [3]. This is illustrated in Table 1, which shows trackside components in different levels of ERTMS-ETCS.

Table 1: Trackside components in different levels of ERTMS-ETCS.

\begin{tabular}{|l|c|c|c|c|c|c|c|c|}
\hline \multirow{2}{*}{ Level } & \multicolumn{7}{|c|}{ Trackside subsystem } \\
\cline { 2 - 9 } & $\begin{array}{c}\text { Track- } \\
\text { side light }\end{array}$ & $\begin{array}{c}\text { Track- } \\
\text { circuit/ } \\
\text { Axle- } \\
\text { counter }\end{array}$ & Balise & LEU & Euroloop & RIU & RBC & GSM-R \\
\hline NTC & $\checkmark$ & $\checkmark$ & $\checkmark$ & $\checkmark$ & - & - & - & - \\
\hline 1 & $\checkmark$ & $\checkmark$ & $\checkmark$ & $\checkmark$ & $\checkmark$ & - & - & - \\
\hline $1+$ RIU & $\checkmark$ & $\checkmark$ & $\checkmark$ & $\checkmark$ & $\checkmark$ & $\checkmark$ & - & $\checkmark$ \\
\hline 2 & - & $\checkmark$ & $\checkmark$ & $\checkmark$ & - & - & $\checkmark$ & $\checkmark$ \\
\hline HL3 & - & $-/ \checkmark$ & $\checkmark$ & $\checkmark$ & - & - & $\checkmark$ & $\checkmark$ \\
\hline
\end{tabular}

Due to railway systems' increasing connectivity and complexity, the railway industry is relying increasingly on modelling, validation and testing to formally evaluate the functionality and safety of railway systems. A variety of different formal tools and languages have been used to accomplish this; however, no formal method dedicated specifically to the needs of the railway industry exists [4]. ERTMS is a multifaceted system and consists of different applications, interfaces, formal tools and languages. To integrate and design multi-tool systems like ERTMS using domain concepts, model-driven engineering is a useful and appropriate method [5].

Global navigation and satellite system (GNSS) is one of the proposed solutions for improved train positioning, but some important questions about safety and architectural arrangements to fulfil ERTMS requirements remain [6]. Some issues related to jamming and spoofing attacks require addressing with robust solutions in order to increase its safety and reliability [7].

Railway systems are known as Cyber Physical Systems (CPS), and they rely on interactions between distributed, connected, computational and physical components. A significant disadvantage of this kind of system is their vulnerability to cyber-attacks and safety issues due to their multimodal complexity. Consequently, cyber security and safety are crucial concerns when seeking to provide secure and reliable railway operation [8], [9].

The implementation of ERTMS to upgrade to a mobile and intelligent railway system thus requires step-by-step and continuous improvement to extant infrastructure and technologies, in combination with or replacement by new technologies (hybrid solutions e.g. HL3) in order to enjoy such benefits as reduced installation, operation and maintenance costs [10].

Table 1 shows which components are included in the trackside subsystem of following ERTMS-ECTS levels: National Train Control System (NTC), Level 1, level 1+ Radio Infill Unit, Level 2 and ERTMS Hybrid Level 3 (HL3). Trackside components include: Line 
Electronic Unit (LEU), Radio Infill Unit (RIU), and Radio Block Centre (RBC). On board subsystems (Table 2) include: Balise Interface Unit (BIU), Train Interface Unite (TIU), Specific Transmission Module (STM), Driver Machine Interface (DMI), European Vital Computer (EVC), Juridical Recording Unit (JUR), and Train Integrity Monitoring System (TIMS).

Table 2: Interfaces and components of ERTMS-ETCS On-board subsystem.

\begin{tabular}{|l|c|c|c|c|c|c|c|c|c|}
\hline \multirow{2}{*}{ Level } & \multicolumn{10}{|c|}{ On-board subsystem } \\
\cline { 2 - 11 } & BIU & TIU & STM & DMI & EVC & Odometry & JUR & TIMS & GSM-R \\
\hline NTC & $\checkmark$ & $\checkmark$ & $\checkmark$ & $\checkmark$ & $\checkmark$ & $\checkmark$ & $\checkmark$ & - & - \\
\hline 1 & $\checkmark$ & $\checkmark$ & $\checkmark$ & $\checkmark$ & $\checkmark$ & $\checkmark$ & $\checkmark$ & $\checkmark$ & - \\
\hline $1+$ RIU & $\checkmark$ & $\checkmark$ & $\checkmark$ & $\checkmark$ & $\checkmark$ & $\checkmark$ & $\checkmark$ & - & $\checkmark$ \\
\hline 2 & $\checkmark$ & $\checkmark$ & $\checkmark$ & $\checkmark$ & $\checkmark$ & $\checkmark$ & $\checkmark$ & - & $\checkmark$ \\
\hline HL3 & $\checkmark$ & $\checkmark$ & $\checkmark$ & $\checkmark$ & $\checkmark$ & $\checkmark$ & $\checkmark$ & $-/ \checkmark$ & $\checkmark$ \\
\hline
\end{tabular}

This study provides an overview of the main topics relevant to ERTMS operation and related issues discussed in recent literature (since 2015). The next section explains the method of study and some preliminary statistics. The third section provides discussion about the study's findings and is followed by a conclusion.

\section{METHODOLOGY}

This literature review is based on a series of database searches using keywords such as "ERTMS OPERATION" and "ERTMS ISSUES" (as shown in Table 3). This literature review analysed 82 papers published since 2015 , and categorises them as main themes, such as: formal methods, adaptable communication systems, GNSS-based train positioning, implementation of ERTMS, cyber security, safety, digitalisation, risk assessment ERTMS, virtual Coupling, human factors, interoperability and Hybrid ERTMS/ETCS Level 3. For each category, the most cited paper was chosen for closer reading and analysis.

Table 4 summarises the methodological guidelines designated for determining applicable papers to include in the review, such as period of publication, characteristics of the paper relevant to this study (including title, and electronic database where found), year, document type (conference, journal, book chapter), and institutional location (country). The results have been presented here as graphs, charts and tables.

Table 3: Search history.

\begin{tabular}{|l|c|c|}
\hline Search string & Search number & Scopus, Springer, Elsevier \\
\hline ERTMS ISSUES & 1 & 38 \\
\hline ERTMS OPERATION & 1 & 44 \\
\hline
\end{tabular}

Table 4: Methodological guidelines.

\begin{tabular}{|l|l|}
\hline Electronic database & Scopus, Springer, Elsevier \\
\hline Time period & $2015-2019$ \\
\hline Collected data & Title, publication channel, document type \\
\hline Additional coding & Country, main theme \\
\hline Output format & Statistical summaries: graphs, charts, tables \\
\hline
\end{tabular}




\section{RESULTS}

This section presents some results from the literature review in the form of graphs, table and chats.

\subsection{Preliminary statistics on 82 papers}

Fig. 1 shows the proportional contribution of countries in the production of literature related to ERTMS. The majority of publications come from Italy, the UK, and France.

Fig. 2 shows the main themes of the publications, and number of publications which conform to each theme. Overall, the studies indicate that formal method is a prioritised issue in terms of the volume of publications dedicated to this topic. There is a high number of academic contributions regarding the formulation modelling and validation of railway and ERTMS subsystems and components.

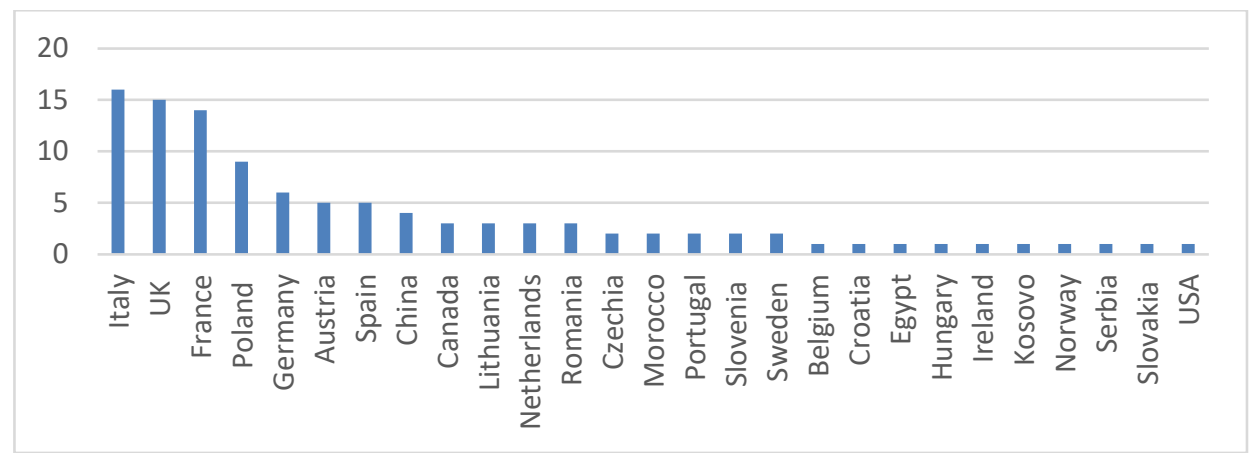

Figure 1: Number of publications by country.

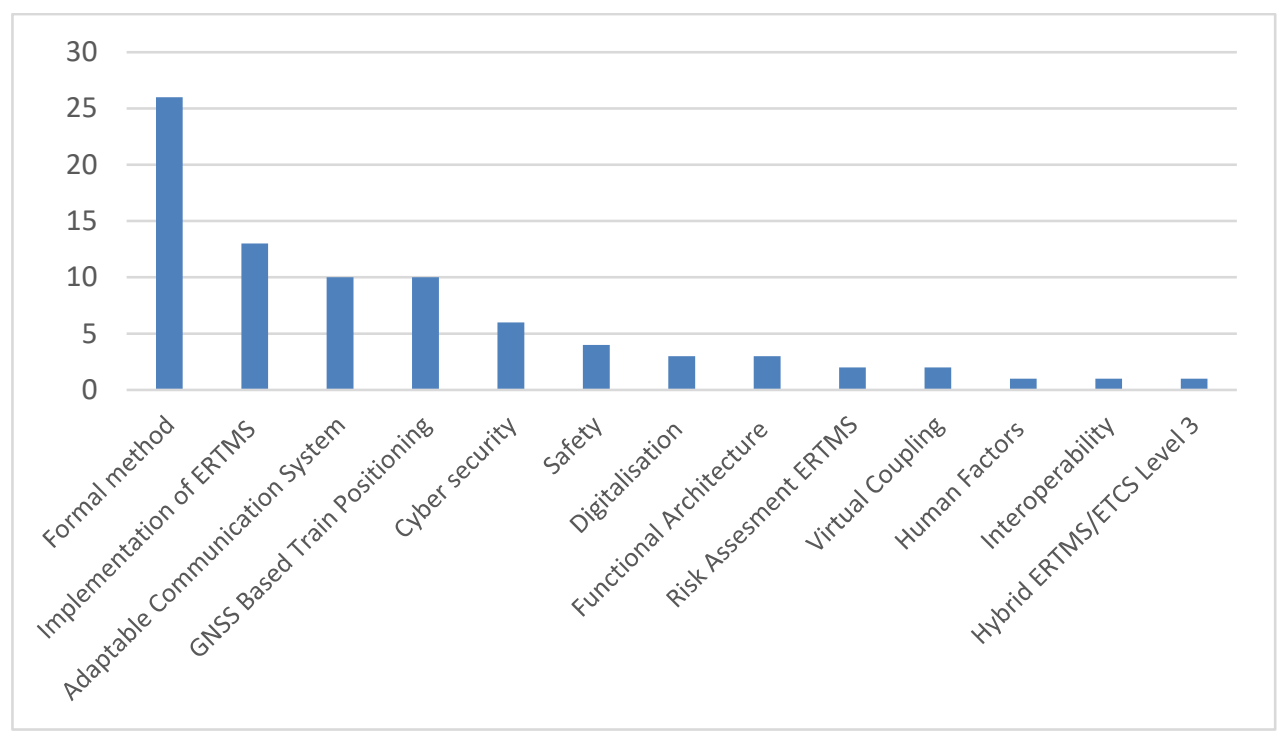

Figure 2: Main themes and their number of publications. 
The following three themes were the next most-represented: the implementation of ERTMS, adaptable communication systems, and GNSS-based train positioning. Regarding adaptable communication systems, there are discussions about replacing the current communication system (GSM-R) with new backward and forward interoperable technologies that provide higher reliability and a greater capacity of data communication.

Table 5 shows the studies' publication years, the number of revised papers. Most of the reviewed papers were published in 2018, and represent a major increase in publication volumes since 2015. Table 6 shows the types of publication channel, the most literature has been published in conferences.

The reviewed studies have been categorised into 12 main themes; for each category, the most-cited or recently-published paper has been studied in depth. These main themes represent key issues to be addressed in future developments of ETRMS, particularly the move towards mobile and intelligent railway transport. Table 7 shows key references for each of the 12 main themes.

Table 5: Year of publication of reviewed papers.

\begin{tabular}{|c|c|}
\hline Year & Number of publications \\
\hline 2019 & 15 \\
\hline 2018 & 40 \\
\hline 2017 & 16 \\
\hline 2016 & 9 \\
\hline 2015 & 2 \\
\hline SUM & 82 \\
\hline
\end{tabular}

Table 6: Year of publication of reviewed papers.

\begin{tabular}{|l|c|}
\hline Type of publication & Number of publications \\
\hline Journal article & 11 \\
\hline Book chapter & 3 \\
\hline Conference paper & 68 \\
\hline SUM & 82 \\
\hline
\end{tabular}

Table 7: Main themes in the reviewed papers and key publications.

\begin{tabular}{|l|l|}
\hline Main theme & Key references \\
\hline Formal methods & Basile et al. [4] \\
\hline Adaptable communication system & Mazzenga et al. [2] \\
\hline GNSS-based train positioning & Beugin et al. [6] \\
\hline Implementation of ERTMS & Kornaszewski et al. [10] \\
\hline Cyber security & Armengaud et al. [11] \\
\hline Safety & Gario et al. [12] \\
\hline Digitalisation & Tokody et al. [8] \\
\hline Risk assessment of ERTMS & Bloomfield et al. [13] \\
\hline Virtual coupling & Flammini et al. [14] \\
\hline Human factors & Naghiyev et al. [15] \\
\hline Interoperability & Rajabalinejad et al. [16] \\
\hline ERTMS-ETCS Hybrid Level 3 & Hoang et al. [3] \\
\hline
\end{tabular}


Formal methods for modelling, testing, and validation play major role. Formal methods can also include semiformal models. Finding a new adaptable communication system is one solution to replace the current communication system, with the aim of enhancing data transmission and the level of service (LOS). The implementation of ERTMS involved several challenges. For example, ERTMS is cyber-physical system, and there is a potential risk of cyber-attacks and other safety issues due to the combined physical and digital nature of this infrastructure. Preparedness and capacity to face issues of cyber security and safety will play an important role in the development of railway communication systems going forward.

Table 8 presents the main themes and related critical issues of the reviewed literature, and which are discussed in greater depth in the next section, along with some proposed solutions.

Table 8: Main themes and related critical issues.

\begin{tabular}{|c|c|}
\hline Main theme & Critical issues \\
\hline Formal methods & $\begin{array}{l}\text { The lack of a unified formal language and method dedicated to } \\
\text { just modelling, verification and validation of railway systems } \\
\text { necessitates the development of a formal tool specific to railways } \\
\text { and moving blocks, with appropriate attributes [4]. }\end{array}$ \\
\hline $\begin{array}{l}\text { Adaptable } \\
\text { communication } \\
\text { system }\end{array}$ & $\begin{array}{l}\text { Increasing demand in railway networks requires the replacement } \\
\text { of GSM-R with FRMCS that provide a higher QOS and capacity } \\
\text { of data transmission. It must be able to guarantee safety } \\
\text { requirements and forward, as well as backwards interoperability } \\
{[1],[2] \text {. }}\end{array}$ \\
\hline $\begin{array}{l}\text { GNSS-based train } \\
\text { positioning }\end{array}$ & $\begin{array}{l}\text { Calculation of potential hazardous situations caused by GNSS } \\
\text { error or hardware/software failure and connection disruption, } \\
\text { safety, and architectural criteria to fulfil ERTMS requirements } \\
\text { [6]. }\end{array}$ \\
\hline $\begin{array}{l}\text { Implementation of } \\
\text { ERTMS }\end{array}$ & Deployment of Intelligent Transport Systems [10]. \\
\hline Cyber security & $\begin{array}{l}\text { Difficulty in assuring the dependability hybrid cyber-physical } \\
\text { systems (CPS) [11]. }\end{array}$ \\
\hline Safety & $\begin{array}{l}\text { Estimate interactions between different data flows and software } \\
\text { layers in order to estimate risk [12]. }\end{array}$ \\
\hline Digitalisation & $\begin{array}{l}\text { Increasing the safety of digitalised systems, e.g. in level crossings } \\
\text { and communication between rail convoys and road vehicles [8]. }\end{array}$ \\
\hline $\begin{array}{l}\text { Risk assessment } \\
\text { ERTMS }\end{array}$ & $\begin{array}{l}\text { Higher connectivity and higher hazardous situation-related } \\
\text { electronic attacks [13]. }\end{array}$ \\
\hline Virtual coupling & $\begin{array}{l}\text { Train-to-train, train-to-wayside subsystem communication and } \\
\text { the replacement of GSM-R with a new communication system } \\
\text { [14]. }\end{array}$ \\
\hline Human factors & Driving models, unfamiliarity with new signalling schemes [15]. \\
\hline Interoperability & $\begin{array}{l}\text { The diversity of goals and operating criteria between national and } \\
\text { international levels for IMs and RUs reduces interoperability and } \\
\text { increases complexity [16]. }\end{array}$ \\
\hline $\begin{array}{l}\text { Hybrid } \\
\text { ERTMS/ETCS } \\
\text { Level } 3\end{array}$ & $\begin{array}{l}\text { Operation of different trains with and without TIMS, on a Virtual } \\
\text { Sub-Section (VSS) and } 12 \text { possible transition states, loss of } \\
\text { connectivity of train communication [3]. }\end{array}$ \\
\hline
\end{tabular}




\section{DISCUSSION}

The development of the European Railway Traffic Management System (ERTMS) throughout Europe over the last two decades to remove the obstacles for providing an interoperable railway network has faced several challenges. This study has aimed to indicate briefly some of the main challenges facing ERTMS by analysing its current architecture and operation. Table 9 is a summary of proposed solutions, as found in the reviewed literature. Significant challenges include the diversity of formal methods, tools, and languages being used to model, formalise, test and validate ERTMS products [4]. An adaptable communication system is needed to replace GSM-R. LTE/4G and 5G have been proposed; with whatever strategy this proceeds, a hybrid system ensuring interoperability with previous and future solutions is critical [1], [2]. GNSS-based train positioning for the calculation of potential hazardous situations, taking into account the principals of safety criteria of railway systems, hybridised architecture, and the calculation of potential hazardous situations are similarly important concerns [6]. Overall, the implementation of ERTMS requires a step-by-step upgrading of the railway system [10].

Table 9: Main themes and proposed solutions.

\begin{tabular}{|c|c|}
\hline Main theme & Proposed solutions \\
\hline Formal method & $\begin{array}{l}\text { Developing a universal formal method for the railway industry } \\
\text { [4]. }\end{array}$ \\
\hline $\begin{array}{l}\text { Adaptable } \\
\text { communication } \\
\text { system }\end{array}$ & $\begin{array}{l}\text { Replacing GSM-R with new solutions, including LTE/4G, 5G or } \\
\text { a hybrid system, to ensure interoperability with previous and } \\
\text { future solutions [1], [2]. }\end{array}$ \\
\hline $\begin{array}{l}\text { GNSS-based train } \\
\text { positioning }\end{array}$ & $\begin{array}{l}\text { For the calculation of potential hazardous situations, taking into } \\
\text { account the principals of safety criteria of railway systems, } \\
\text { hybridised architecture, and the calculation of potential hazardous } \\
\text { situations [6]. }\end{array}$ \\
\hline $\begin{array}{l}\text { Implementation of } \\
\text { ERTMS }\end{array}$ & Step-by-step upgrading of the railway system [10]. \\
\hline Cyber security & $\begin{array}{l}\text { Designing proper tools to guarantee the safety and dependability } \\
\text { of Cyber-Physical Systems (CPS) [11]. }\end{array}$ \\
\hline Safety & $\begin{array}{l}\text { Employing clear graphical presentation of safety data and } \\
\text { predicted interactions between different data flows and software } \\
\text { layers to effectively estimate risk [12]. }\end{array}$ \\
\hline Digitalisation & $\begin{array}{l}\text { Equip trains and road vehicles with automatic protection systems } \\
\text { [8]. }\end{array}$ \\
\hline $\begin{array}{l}\text { Risk assessment } \\
\text { ERTMS }\end{array}$ & $\begin{array}{l}\text { Higher connectivity and a higher number of hazardous situations } \\
\text { caused by electronic attacks require the improvement of security } \\
\text { in connected systems [13]. }\end{array}$ \\
\hline Virtual coupling & Replacing GSM-R with new communication systems (5G) [14]. \\
\hline Human factors & $\begin{array}{l}\text { Training train drivers to address knowledge gaps between drivers } \\
\text { and new train driving models [15]. }\end{array}$ \\
\hline Interoperability & Stabilise technical specification by a unique designer entity [16]. \\
\hline $\begin{array}{l}\text { Hybrid ERTMS/ } \\
\text { ETCS Level } 3\end{array}$ & $\begin{array}{l}\text { Guaranteeing operation without collision by hazard mitigation of } \\
\text { the system [3]. }\end{array}$ \\
\hline
\end{tabular}


In the field of cyber security, the assurance of dependability of Cyber-Physical Systems (CPS) relies on the design of proper tools [11]. These must be capable of estimating the interactions between different data flows and layers of software in order to effectively estimate risk and present this in a clear, graphical form [12]. Increasing the safety of digitalised systems, e.g. in level crossings and communication between rail convoys and road vehicles, likewise needs to be addressed [8]. Risk assessment studies show that higher connectivity and an increasing incidence of hazardous situations due to electronic attacks requires the improvement of security in connected systems [13]. In the area of virtual coupling, train-to-train and train-to-wayside subsystem communication systems are at risk of failure because of the current GSM-R; these must be replaced with a new communication system, perhaps one based on 5G technology [14]. The unfamiliarity of train drivers with new driving models and new signalling schemes can be addressed through increased professional training [15]. The diversity of goals between nations and at the international level for IMs and RUs reduces interoperability and increases complexity. Rajabalinejad et al. propose to stabilise technical specification through the creation of a unique designer entity [16].

Some challenges related to Hybrid ERTMS/ETCS Level 3 include the operation of different trains with and without TIMS on a VSS, different possible transition states, loss of connectivity of train communication, and ghost and shadow trains. Addressing these challenges will require guaranteeing operation without collision by moderating risk within the system [3].

\section{CONCLUSION}

This study has presented an overview of the main issues discussed in recent research. The studies reviewed illustrate that in order to simplify the interaction of components and subsystems of ERTMS, to reduce the cost of implementation and maintenance, and to increase interoperability, it is necessary to reduce the number of wayside components and pivot the system as a whole toward mobile equipment, autonomous trains, and decentralised communication. In the area of formalisation, it is necessary to develop a robust and reliable tool for more standardised modelling, formalisation, testing and validation of critical safety systems specific to the needs of the railway industry and to be used by all involved parties. To address knowledge gaps between human operators and new technologies, reduce human error, and increase performance, an emphasis on developing the skills of railway employees and operators with new technologies is highly recommended. In order to save and build upon previous investments in ERTMS, it is necessary to pursue hybrid solutions and gradually update current systems in order to guarantee backwards and forwards interoperability.

\section{REFERENCES}

[1] Canonico, R., Marrone, S., Nardone, R. \& Vittorini, V., A framework to evaluate 5G networks for smart and fail-safe communications in ERTMS/ETCS. Reliability, Safety, and Security of Railway Systems. Modelling, Analysis, Verification, and Certification, eds. A. Fantechi, T. Lecomte \& A. Romanovsky, Springer: Cham, 2017.

[2] Mazzenga, F. et al., The adoption of public telecom services for the evolution of the ERTMS-ETCS train control systems: Challenges and opportunities. Communication Technologies for Vehicles, eds. M. Kassab, M. Berbineau, A. Vinel, M. Jonsson, F. Garcia \& J. Soler, Springer: Cham, 2015.

[3] Hoang, T.S., Butler, M. \& Reichl, K., The Hybrid ERTMS/ETCS Level 3 case study. Abstract State Machines, Alloy, B, TLA, VDM, and Z. ABZ 2018, eds. M. Butler, A. Raschke, T. Hoang \& K. Reichl, Springer: Cham, 2018. 
[4] Basile D. et al., On the industrial uptake of formal methods in the railway domain. Integrated Formal Methods. IFM 2018, eds. C. Furia \& K. Winter, Springer: Cham, 2018.

[5] Bernardi, S. et al., Towards a model-driven engineering approach for the assessment of non-functional properties using multi-formalism. Software and Systems Modeling, 18, pp. 2241-2264, 2019. https://doi.org/10.1007/s10270-018-0663-8.

[6] Beugin, J. Legrand, C., Marais, J., Berbineau, M. \& El-Koursi, E., Safety appraisal of GNSS-based localization systems used in train spacing control. IEEE Access, 6, pp. 9898-9916, 2018.

[7] Neri, A. et al., An anti-jamming and anti-spoofing digital beamforming platform for the GNSS-based ERTMS train control system. Proceedings of the 30th International Technical Meeting of the Satellite Division of The Institute of Navigation (ION GNSS+ 2017), Portland, Oregon, pp. 3538-3556, 2017.

[8] Tokody, D., Mezei, I.J. \& Schuster, G., An overview of autonomous intelligent vehicle systems. Vehicle and Automotive Engineering. Lecture Notes in Mechanical Engineering, eds. K. Jármai \& B. Bolló, Springer: Cham, 2017.

[9] Schmittner, C. et al., Threat modeling in the railway domain. Reliability, Safety, and Security of Railway Systems. Modelling, Analysis, Verification, and Certification, eds. S. Collart-Dutilleul, T. Lecomte \& A. Romanovsky, Springer: Cham, 2019.

[10] Kornaszewski, M., Chrzan, M. \& Olczykowski, Z., Implementation of new solutions of intelligent transport systems in railway transport in Poland. Smart solutions in today's transport. TST 2017. Communications in Computer and Information Science, ed. J. Mikulski, Springer: Cham, 2017.

[11] Armengaud, E. et al., DEIS: Dependability Engineering Innovation for Industrial CPS. Advanced Microsystems for Automotive Applications 2017, eds. C. Zachäus, B. Müller \& G. Meyer, Springer: Cham, 2018.

[12] Gario, A., Andrews, A. \& Hagerman, S., Fail-safe testing of safety-critical systems: a case study and efficiency analysis. Software Quality Journal, 26, pp. 3-48, 2018.

[13] Bloomfield, R., Bendele, M., Bishop, P., Stroud, R. \& Tonks, S., The risk assessment of ERTMS-based railway systems from a cyber security perspective: Methodology and lessons learned. Reliability, Safety, and Security of Railway Systems. Modelling, Analysis, Verification, and Certification. RSSRail 2016, eds. T. Lecomte, R. Pinger \& A. Romanovsky, Springer: Cham, 2016.

[14] Flammini, F., Marrone, S., Nardone, R., Petrillo, A., Santini S. \& Vittorini, V., Towards railway virtual coupling. 2018 IEEE International Conference on Electrical Systems for Aircraft, Railway, Ship Propulsion and Road Vehicles \& International Transportation Electrification Conference (ESARS-ITEC), pp. 1-6, 2018.

[15] Naghiyev, A., Sharples, S., Ryan, B., Coplestone, A. \& Carey, M., Expert knowledge elicitation to generate human factors guidance for future European Rail Traffic Management System (ERTMS) train driving models. Proceedings of the Institution of Mechanical Engineers, Part F: Journal of Rail and Rapid Transit, 231(10), pp. 11411149, 2017. https://doi.org/10.1177/0954409717695902.

[16] Rajabalinejad, M. \& Schuitemaker, K., ERTMS Challenges for a safe and interoperable European railway system. PESARO 2017. The Seventh International Conference on Performance, Safety and Robustness in Complex Systems and Applications, pp. 17-22, 2017. 